LÍNGUA PORTUGUESA 


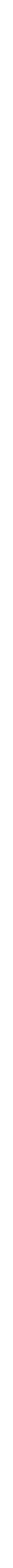




\section{A dança da ortografia}

Lúcia Fulgêncio

Universidade Federal de Minas Gerais

Mário A. Perini

Universidade Federal de Minas Gerais

\section{- Retomando a dança}

Assistimos recentemente (2009) à última rodada de reformas da ortografia portuguesa. Nessa oportunidade, vale fazer duas perguntas importantes:

(a) que problemas essa nova versão da ortografia procura resolver?

(b) até que ponto esses problemas foram resolvidos?

Vamos começar com um breve histórico das reformas ortográficas do século XX.

A ortografia portuguesa foi bastante estável no período que vai do século XVII ao XIX, definindo-se, na época, como parcialmente etimológica. Baseava-se em uma etimologia apenas em parte adequada, conforme foi apontado por muitos autores; mas atendia às modas da época, e seguia o exemplo do francês embora não o do espanhol e do italiano, que optaram por ortografias muito mais próximas da pronúncia da língua, sem tentar representar na escrita traços da origem histórica das palavras. Seguir o exemplo francês era o normal para a intelectualidade portuguesa nesse período, e assim como usavam cabeleiras ao estilo de Paris, os portugueses de 1750 ortografavam mais ou menos à maneira dos escritores franceses do tempo. 
Em 1911, na onda de entusiasmo da nova República Portuguesa, tentou-se pela primeira vez estabelecer uma ortografia oficial. O resultado foi algo não muito diferente da ortografia de hoje, mas que só foi adotado em Portugal, tendo sido ignorado pelos brasileiros, que continuaram a escrever etimologicamente. Estava iniciada a dança: daí em diante, viriam as novas reformas, regularmente espaçadas em intervalos de aproximadamente 30 anos: 1911, 1943-45, 1971, 2009. Uma observação importante a respeito dessas reformas é que em nenhuma dessas ocasiões os brasileiros e portugueses chegaram a um verdadeiro acordo: em todos os casos, e durante todo esse período, a ortografia dos dois países foi, e continua sendo, diferente. Ou seja, o termo "acordo ortográfico" expressa uma intenção, não um fato.

Aqui vamos examinar a última dessas reformas, a que entrou em vigor em 2009, em comparação com a ortografia baseada na reforma de 1971; e vamos nos concentrar na versão brasileira, com apenas algumas notas sobre a versão lusitana. Conforme tentaremos mostrar, as respostas às duas perguntas básicas formuladas acima não são muito animadoras. Os responsáveis pela reforma não identificaram os verdadeiros problemas da ortografia; e mesmo na limitadíssima extensão da reforma não conseguiram, no conjunto, trazer melhorias. A conclusão é que a ortografia de 1971, com seus graves defeitos, é ainda um pouco melhor do que a de 2009, que representou um passo atrás na maioria dos detalhes.

\section{O valor de uma ortografia oficial}

A ortografia não é um construto teórico para uso dos pesquisadores, nem um objeto de contemplação estética. É um instrumento prático utilizado pela totalidade da população que lê e escreve - o que no Brasil significa muitas dezenas de 
milhões de pessoas. É o veículo da língua escrita, em todas as suas manifestações, em obras literárias, textos técnicos, livros didáticos, jornais e revistas, cartas pessoais, avisos e outdoors, bulas de remédios, folhetos de instruções, circulares de serviço, mensagens de internet, artigos acadêmicos e redações escolares. É também (e aqui podemos ficar a favor ou contra) usada como instrumento de filtragem social, quando exigimos que o cidadão domine a ortografia para assumir um emprego de policial, motorista ou engenheiro. Assim, é conveniente para uma nação - ou um conjunto de nações - dispor de uma ortografia unificada; isso explica a atenção dada pelos governos ao problema de como escrever as palavras da língua. A ortografia é a expressão da língua escrita padrão, que é bastante uniforme no Brasil. Por outro lado, se a ortografia é um instrumento a ser dominado (idealmente) pela totalidade da população, convém que seja simples e racional, tão fácil de aprender quanto possível. Essa consideração esteve na base das sucessivas reformas executadas: entendeu-se, com razão, que em vez de escrever philosophia (porque a palavra vem do grego, e o $\varphi$ grego se transcrevia como $p h$ em português), é mais fácil escrever filosofia, mais ou menos "como se pronuncia" (só mais ou menos: seria melhor filozofia, claro).

Até aí funciona o bom senso. Mas, por alguma razão, os reformadores da ortografia não conseguiram se liberar de todo das considerações etimológicas: eliminaram o ph, mas conservaram as várias maneiras de grafar o fonema /s/:c, ç, $s$, ss, sc, sç, $x c, z$, como em cedo, aço, sede, assar, nascer, cresça, exceto e paz; ou o fonema /3/:j, g, como em jeito e gente etc. Ou seja, não conseguiram elaborar uma ortografia fonologicamente (ou, talvez melhor, morfofonologicamente) consistente. Com isso, ainda temos que "saber" que cidade tinha $c$ em latim, mas sete tinha $s$ - na verdade, acabamos aprendendo esses casos um a um, sem levar em conta a origem das palavras. 
A grande oportunidade para livrar a ortografia dessas inconsistências surgiu, a nosso ver, em 1943, quando se realizou a limpeza principal dos elementos etimológicos. A reforma foi excessivamente tímida, e a oportunidade foi perdida. Com pequenas alterações, a ortografia de 1943 é a que vigora até hoje no Brasil.

Não é nosso objetivo estudar promenorizadamente as reformas da ortografia. Depois de um breve histórico desde 1943, vamos concentrar nossa atenção no acordo de 2009 para avaliá-lo em termos de suas diferenças do sistema de 1971, procurando verificar se houve progresso.

\section{De 1943 a 1971}

Vamos adiantar nossa opinião: não houve progresso. As mudanças foram muito pequenas, e em geral representam um retrocesso, ou seja, a ortografia de 2009 é um pouco pior do que a de 1971.

Para ver isso vamos relembrar que a ortografia não é um sistema criado por especialistas para uso de especialistas. É algo que precisa ser aprendido e utilizado com eficiência pela população do país. E para que funcione eficientemente deve se basear, na medida do possível, naquilo que a população já domina: a língua falada, o português brasileiro. ${ }^{1}$ Para dar um exemplo, se pronunciamos "falar" e "calar" - duas palavras que só diferem na consoante inicial - é conveniente que se escrevam essas palavras com apenas essa diferença, no caso a primeira letra. Até 1943 se escrevia fallar e calar - mas essa diferença entre

${ }^{1}$ Dizemos "na medida do possível" porque há variação regional de pronúncia, que não poderia ser considerada em uma ortografia padrão. Devemos então nos contentar com uma aproximação, sem pretender chegar a uma representação fonológica exata. 
um $l$ e dois $l l$ não corresponde a nada na língua falada, precisava ser aprendida e constituía na verdade conhecimento inútil. Era uma fonte de erros que não rendia nada de proveitoso.

Pode-se argumentar que distinguindo $l$ de $l l$ a escrita fica mais próxima de suas origens latinas. Há duas objeções sérias contra isso: primeiro, que vantagem há em ficar mais próximo do latim, se o que falamos é português? A outra objeção (no caso deste exemplo) é que simplesmente a etimologia está errada, porque a palavra latina que nos deu falar é fabulare, com um $l$ só e uma sílaba -bu- a mais. Por que não escrever, então, fabulare e pronunciar "falar"? Assim ficaríamos ainda mais próximos do latim. A conclusão é que a ortografia, para ser útil, deve se aproximar não do latim (ou do indoeuropeu, ou do malgaxe, ou do vietnamita) mas do português moderno.

Isso foi reconhecido pelos reformadores de 1943 e etapas seguintes: por isso eliminaram o ph, o th, o y (como em physica > física, thema > tema), assim como as letras duplas sem motivação, como $l l, t t, n n$, as consoantes não pronunciadas, como as de abstracção (>abstração), adoptar (> adotar) etc. Mas por alguma razão só foram até certo ponto; não tiveram a motivação (ou a coragem) de grafar de maneira única o fonema /s /, como vimos acima; conservaram a inútil diferença entre $x$ em xícara e ch em China, além dos diferentes valores fonológicos da letra $x$ (xícara, fixo, exame, próximo); mantiveram letras mudas como o $h$ inicial de harpa; a letra g com seus dois valores (gato, gelo), um dos quais redundante, pois já temos o $j$; as duas maneiras de grafar o fonema $/ \mathrm{k} /$, como em casa e queijo; a diferença puramente gráfica de finais de palavras em -em (correm) e -en (hífen); a diferença de finais átonos em-am (andam) e-ão (órgão). Essas redundâncias têm como único efeito aumentar a dificuldade de uso e aprendizagem da ortografia. Outras são mais desculpáveis: pode-se manter a diferença entre $e$ e ei que se vê em seja e beija, ou cera e feira, ou a diferença entre lh e li de ilha e família, ou ainda a 
distinção entre vil e viu, porque correspondem a pronúncias reais, embora raras no Brasil.

De qualquer modo, pode-se concluir que a reforma de 1943 (bastante semelhante à lusitana de 1911) representou um progresso, mas um progresso bastante tímido, resolvendo alguns problemas sem tocar em outros, arbitrariamente selecionados. Pode-se dizer que daí em diante muito pouco foi feito, em geral de efeito nulo ou negativo: as ortografias de 1971 e 2009 conservam em grande parte o padrão proposto em 1943, com alterações relativamente pequenas.

\section{A reforma de 2009}

Passamos agora a um exame das mudanças introduzidas pela reforma de 2009. Na verdade, a reforma foi elaborada em 1990, mas só entrou em vigor quase 20 anos depois. Essa reforma é geralmente chamada "Acordo Ortográfico", designação incorreta, porque não houve acordo, e as ortografias do Brasil e de Portugal continuam diferentes.

Em comparação com a ortografia vigente desde 1971, a nova reforma mudou os seguintes pontos:

(a) eliminou o trema: aguentar em vez de agüentar;

(b) eliminou o acento diferencial de palavras como pára (do verbo parar) e para (preposição);

(c) suprimiu o acento agudo dos ditongos ói e éi em palavras paroxítonas: heroico em vez de heróico; ideia em vez de idéia. Note-se que foi mantido o acento nos mesmos ditongos se a palavra é oxítona - de modo que se escreve heroico e herói: uma palavra sem acento, a outra com acento;

(d) suprimiu o acento agudo de i e u tônicos depois de ditongo:feiura em vez de feiúra; 
(e) suprimiu o acento agudo do u tônico nos grupos gue, gui, que ocorrem em certas formas verbais: arguem (antes argúem), argui (antes argúi);

(f) suprimiu o acento circunflexo das palavras terminadas em eem e oo(s): veem em vez de vêem (do verbo ver); voo em vez de vôo;

(g) acrescentou três letras ao alfabeto: k, w, y;

(h) procurou sistematizar (sem sucesso, como veremos) o uso do hífen em prefixos e locuções. ${ }^{2}$

A seguir, vamos examinar esses pontos.

\section{Eliminação do trema}

A eliminação do trema representa um afastamento entre a escrita e a fala; não gera dificuldades para a escrita, mas sim para a pronúncia. Assim, digamos que uma pessoa só conhece a palavra quinquênio através da escrita. Não tem meio de saber se se pronuncia qüinquênio, ou quinqüênio, ou qüinqüênio, ou ainda quinquênio. Como se vê, a ortografia precedente fornece mais informação sobre como pronunciar certas palavras. Temos que concluir que a ortografia de 1971 é superior à de 2009 neste particular. Por outro lado, se consideramos que os falantes da língua geralmente sabem como se pronunciam as palavras, a falta do trema não causa grandes problemas. Ninguém pronunciaria pinguim sem o $u$, só porque não tem trema. Claro, todo mundo sabe como é a pronúncia, e ela não é determinada pela escrita. Aqui o inconveniente afeta mais os estrangeiros, que não conhecem a pronúncia, e os falantes do português apenas quando se trata de uma palavra desconhecida, ou uma daquelas que a gente só conhece pela escrita.

${ }^{2}$ Não consideramos aqui o uso do hífen com elementos clíticos, como em ajudou-me, fazê-lo-ia, que não sofreu alteração. 


\section{Eliminação do acento diferencial em pára etc.}

Aqui a ortografia de 2009 aproxima a fala da escrita, portanto este é um traço positivo. Deve-se notar, contudo, que essa vantagem só interessa um pequeno número de palavras: pára > para (do verbo parar); péla > pela (do verbo pelar); pólo > polo (como em Pólo Sul, agora Polo Sul) e mais umas poucas.

\section{Supressão do acento em heroico}

Aqui a ortografia de 1971 é superior. De acordo com ela, acentuam-se os ditongos ói, éi e éu onde quer que ocorram; assim, aprende-se uma regra apenas. Já a de 2009 estabelece que esses ditongos são acentuados em palavras oxítonas, mas não em paroxítonas, como em boia (anteriormente bóia), Andreia (anteriormente Andréia). Temos agora duas regras em vez de uma. Outra coisa que não ficou explicada é por que suprimir o acento apenas nas paroxítonas: herói é acentuado, heroico não. $\mathrm{E}$, naturalmente, introduz-se mais um elemento de afastamento entre grafia e fonologia: Andreia não rima com feia, mas graficamente parece que sim.

\section{Supressão do acento em feiura}

Aqui a revisão de 2009 eliminou um acento realmente inútil, já que a grafia feiura não deixa dúvidas quanto à pronúncia da palavra. Se houvesse palavras com acento na vogal do meio (algo como feíura), essas mereceriam acento, mas aparentemente não existem. Novamente, o número de palavras afetadas é muito pequeno.

\section{Supressão do acento agudo em gue, gui}

Essa mudança interessa formas verbais como averigue, argui, que se pronunciam com o $u$ tônico. Aqui a ortografia de 1971 é mais consistente, pois representa uma diferença de 
pronúncia que a de 2009 escamoteia. Por exemplo, pela ortografia de 2009 as palavras que se escreviam sagüi, segui e argúi passam a se escrever sagui, segui e argui, todas com a mesma terminação gui, embora, claro, continuem a se pronunciar diferentemente.

\section{Supressão do circunflexo em voo, veem etc.}

Neste caso a ortografia de 2009 apresenta uma inovação conveniente, porque o circunflexo nesses casos não cumpria nenhuma função.

\section{Acréscimo de $k, w$ e $y$ ao abecedário}

Esta não é uma inovação ortográfica, mas simplesmente burocrática, e sem nenhum efeito na escrita - aliás sem nenhum efeito nos dicionários. O Aurélio de 1986 consigna essas três letras em seus lugares respectivos, e por exemplo observa que o $k$ é uma "letra considerada como pertencente ao nosso alfabeto", ${ }^{3}$ o que dá a entender que o acréscimo nem sequer é real: as letras já estavam lá, e lá permanecem.

\section{O hífen}

As regras de uso do hífen merecem uma seção especial, em virtude de seu caráter caótico em todos os sistemas ortográficos adotados até hoje. Nesse particular, a ortografia de 2009 não fez mais que substituir um sistema impraticável por outro, igualmente impraticável; ficamos imaginando porque se deram ao trabalho de mudar. Os brasileiros vão continuar tendo que memorizar os casos de uso do hífen um a um.

${ }^{3}$ Aurélio (1986, pág. 998). 
O texto oficial do Acordo Ortográfico, ${ }^{4}$ no que se refere ao hífen, é cheio de regras e subregras ${ }^{5}$ e exceções arbitrárias. Por exemplo,

Emprega-se o hífen nas palavras compostas por justaposição que não contêm formas de ligação [...] [Academia, 2009, p. XXVI]

No entanto, o próprio Vocabulário Ortográfico admite formas como barriga-d'água, que contém uma forma de ligação e tem hífen. Outro exemplo é

Emprega-se o hífen nos topónimos/topônimos ${ }^{6}$ compostos iniciados pelos adjetivos grã, grão ou por forma verbal ou cujos elementos estejam ligados por artigo. [Academia, 2009, p. XXVI]

Podemos começar questionando esses "adjetivos" grã e grão. Que adjetivos são esses, que só podem aparecer em compostos? ${ }^{7}$ Por outro lado, a limitação a compostos que incluem forma verbal é perfeitamente gratuita. Ela nos obriga a escrever Abre-Campo e Ouro Preto, Passa-Quatro e Belo Horizonte etc. ${ }^{8}$ Esse tipo de regra se

${ }^{4}$ Assinado pela Comissão de Lexicografia da Academia Brasileira de Letras; uma pergunta óbvia é por que essa tarefa foi confiada a uma organização sem credenciais científicas, quando há no país dezenas de universidades dotadas de departamentos de Linguística idôneos e linguistas competentes?

${ }^{5}$ É assim que o Acordo manda escrever; o fato de que a pronúncia é sub-regra não conta. Assim, escreve-se abrogar (anteriormente $a b$ rogar) como abrir, ocultando uma diferença de pronúncia.

${ }^{6}$ Sic. Como não houve acordo real, o Vocabulário optou por registrar, mesmo no meio de um texto, as formas aceitas em Portugal e no Brasil. Será que essa é uma regra geral, válida para todos os textos?

${ }^{7}$ Estamos falando do português do século XXI, evidentemente.

${ }^{8}$ Será que existe mesmo uma "forma verbal" em Passa-Quatro? 
repete nas páginas seguintes, mantendo o uso do hífen como o pesadelo que sempre foi. E, uma vez dominadas as regras, há as exceções, como

Nas locuções de qualquer tipo, sejam elas substantivas, adjetivas, pronominais, adverbiais, prepositivas ou conjuncionais, não se emprega em geral o hífen, salvo algumas exceções já consagradas pelo uso [...] [Academia, 2009, p. XXVII; itálico nosso]

Seria o caso de perguntar por que só aqui se mostra esse respeito pelo uso tradicional, já que em outros casos esse mesmo uso é reformulado. Para ter uma ideia clara da situação, o leitor é convidado a percorrer (e tentar memorizar) as regras, subregras e exceções nas páginas XXVI-XXIX do VOLP (Academia, 2009). Essas subregras são às vezes bastante difíceis de aplicar, mesmo para um linguista profissional, como:

Certos compostos, em relação aos quais se perdeu, em certa medida, a noção de

composição, grafam-se aglutinadamente: girassol [...] paraquedas, etc. [Academia, 2009, p. XXVI]

"Em certa medida" é um primor de vaguidão: como vamos saber quando é que a medida está completa? E como distinguir paraquedas, dado na página XXVI como sem hífen pela razão aventada acima, de para-lama, dado com hífen na página 619 do mesmo Vocabulário?

Mas digamos que o leitor seja uma dessas pessoas persistentes e estudiosas, e acabe realmente aprendendo todos os meandros do sistema. Aí ele ainda terá que enfrentar bom número de exceções e simples inconsistências, como por exemplo:

cara de pau, maria vai com as outras, pé de chinelo sem hífen, mas rato-de-esgoto, rato-de-barriga-branca com hífen. Isso porque nomes de animais e plantas têm hífen; por que esse 
privilegiamento de espécies biológicas? O texto não explica;

barata-descascada tem hífen, mas barata tonta não tem;

alta-fidelidade e alta-tensão têm hífen, alta classe e alto escalão não;

ágnus-dei tem hífen; será que é porque tem origem latina? Mas avis rara não tem hífen;

bem-me-quer tem hífen, malmequer não tem.

E assim por diante. Se quisermos realmente uma regra operacionalizável para o uso do hífen segundo o Acordo de 2009, podemos usar a seguinte:

O hífen é usado quando a palavra está consignada com hífen no Vocabulário Ortográfico da Lingua Portuguesa.

O VOLP é um livro de 877 páginas, em tamanho grande $(21 \mathrm{~cm} \times 28 \mathrm{~cm})$, e pesa cerca de $2 \mathrm{~kg}$; um pouco grande para levar com a gente por toda parte.

\section{Conclusão}

Concluindo: o último passo da dança da ortografia se salda, no final, como essencialmente uma perda de tempo. Não, não apenas de tempo: uma perda de recursos e esforços que seriam muito melhor aplicados em outros aspectos da educação. $\mathrm{Na}$ nossa opinião, a reforma tem as marcas de um trabalho amadorístico, mais preocupado com acomodações políticas do que com a busca de vantagens linguísticas e educacionais. E será que dentro de 30 anos o baile vai recomeçar? 


\section{Referências}

Academia Brasileira de Letras. Vocabulário ortográfico da língua portuguesa (VOLP). 5. ed. Rio de Janeiro: Global, 2009.

FERREIRA, Aurélio Buarque de Holanda. Novo dicionário da língua portuguesa (Aurélio). 2. ed. Rio de Janeiro: Ed. Nova Fronteira, 1986.

\section{Resumo}

A reforma ortográfica de 2009 apresenta vantagens em relação à ortografia anterior? Houve algum ganho, alguma melhoria do ponto de vista linguístico? O presente artigo procura discutir essas questões, a partir da análise das novas regras impostas pela reforma ortográfica de 2009. A conclusão a que se chega é que andamos para trás - ou seja, o suposto "acordo ortográfico" não existe (uma vez que Brasil e Portugal continuam a grafar distintamente várias palavras) e, grosso modo, o sistema ortográfico aprovado em 2009 é pior do que o que estava anteriormente em vigor.

\section{Abstract}

Does the 2009 spelling reform bring any advantage over the previous system, adopted in 1971? Was there any improvement from the linguistic point of view? This article discusses these questions by analyzing the spelling rules established by the 2009 reform, and comes to the conclusion that there was no progress. The so-called "orthographic agreement" (between the Portuguese-speaking countries) does not exist, since the systems used in Brazil and Portugal remain different; and the 2009 spelling system is, on the whole, less adequate than the system previously in use. 


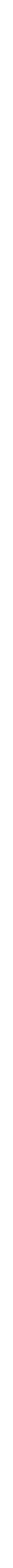

